\title{
ANÁLISIS DE LA VULNERABILIDAD SOCIAL Y DE GÉNERO EN LA DÍADA MIGRACIÓN Y VIH/SIDA ENTRE MUJERES MAYAS DE YUCATÁN
}

\author{
Rocío QUINTAL LÓPEZ \\ Ligia Vera Gamboa \\ Centro de Investigaciones Regionales “Dr. Hideyo Noguchi”, \\ Universidad Autónoma de Yucatán
}

\begin{abstract}
Resumen: En el presente artículo se exponen y analizan una serie de condiciones sociales, tanto materiales como simbólicas, de la vida de mujeres mayas, parejas de migrantes, que configuran escenarios de vulnerabilidad social y de género que incrementan su potencial adquisición de VIH/sida. Se abordan asimismo temas como el acceso a la educación y la salud, el sistema de creencias, significados y prácticas en torno al cuerpo, sexualidad y vida en pareja, así como sus conocimientos y significados acerca del $\mathrm{VIH} /$ sida, sus mecanismos de transmisión y formas de prevención. Concluimos analizando su percepción de riesgo y prácticas de autocuidado ante el VIH y las infecciones de transmisión sexual. Esta información permite vislumbrar estrategias de prevención que sean pertinentes y eficaces en función de las necesidades y contextos de las mujeres investigadas.
\end{abstract}

Palabras Clave: VIH/sida, migración, vulnerabilidad social, género, mujeres mayas.

AвSTRACT: This article describes and analyzes a series of social conditions, both material and symbolic, in the lives of Mayan women with migrant partners, which create situations of social and gender vulnerability that increase their potential of acquiring HIV/AIDS. It analyzes the women's access to education and healthcare, their system of beliefs, meanings, and practices in relation to their body, their sexuality and family life, as well as their knowledge and understanding about HIV/AIDS, their transmission mechanisms and forms of prevention. It concludes by analyzing the women's risk perception of HIV/AIDS and the daily forms of self-care they employ to prevent STDs. This information should be useful for envisioning relevant and effective intervention strategies for prevention purposes, which target Mayan women with migrant partners.

KEYwORDs: HIV/Aids, migration, social vulnerability, gender, mayan women.

RECEPCIÓN: 14 de mayo de 2014.

ACEPTACIÓN: 26 de septiembre de 2014. 


\title{
ANÁLISIS DE LA VULNERABILIDAD SOCIAL Y DE GÉNERO EN LA DÍADA MIGRACIÓN Y VIH/SIDA ENTRE MUJERES MAYAS DE YUCATÁN
}

\author{
Rocío QuiNTAL LóPEZ \\ Ligia Vera Gamboa \\ Centro de Investigaciones Regionales “Dr. Hideyo Noguchi”, \\ Universidad Autónoma de Yucatán
}

\section{Introducción}

Si bien el fenómeno migratorio en Yucatán se ha calificado como emergente en comparación con otros estados de la República Mexicana considerados tradicionalmente expulsores de migrantes, el ritmo de crecimiento de éstos en el estado pasó del $0.40 \%$ de la población en el 2000 al $1.80 \%$ en el 2005 , lo que representa un incremento del 39.1\% en tan sólo cinco años (INDEMAYA, 2008). Los migrantes, en su gran mayoría, provienen del $48.5 \%$ de la población que se encuentra en situación de pobreza (de los cuales el $11.7 \%$ en situación de pobreza extrema). Los factores de vulnerabilidad social de esta población — rezago educativo, baja calidad y problemas en el acceso a los servicios de salud, seguridad social, vivienda y alimentación — siguieron aumentado durante el año 2010 (CONEVAL, 2012).

La marginación y el rezago que se vive en Yucatán han propiciado que cada vez más habitantes de los municipios del interior del estado emigren, bien a nivel regional, bien nacional e internacional. Los datos indican que esta tendencia es de carácter ascendente. La comprensión de la dinámica migratoria a nivel regional, las variables que la potencian y sus impactos económicos, sociales y culturales son esenciales para planear políticas públicas capaces de intervenir y, en la medida de lo posible, prevenir la gama de consecuencias negativas que este fenómeno ya está desencadenando.

Tal es el caso de lo que ocurre con el tema de la salud de los migrantes y sus familias. En lo que al VIH/sida se refiere, diversos estudios concluyen que la potencial adquisición de esta enfermedad se redimensiona a la luz de la migración. Esto en la medida que la condición migratoria crea contextos de vulnerabilidad en los que es más factible que se lleven a cabo prácticas de riesgo asociadas a la adquisición de dicha enfermedad entre los migrantes (Bronfman, Uribe, Halperin y Herrera, 2001; Bronfman y Leyva, 2008) pero también entre sus parejas, que los esperan en las comunidades de origen (Leyva y Caballero, 2009; Flores-Palacios, 2013, Quintal y Vera, 2014). Entre las condiciones que delinean y configuran los 
escenarios de vulnerabilidad vinculados a la potencial adquisición de $\mathrm{VIH} / \mathrm{sida}$ en contextos migratorios resalta de manera particular la dimensión del género, que cruza las otras condiciones de vulnerabilidad que se han identificado, tales como la etnicidad, la educación y el acceso a los servicios de salud, entre otras.

Las investigaciones sobre la díada salud-migración en el escenario yucateco son muy escasas. En consecuencia, también lo son las políticas públicas, programas y acciones que den respuesta a las necesidades que se generan en materia de prevención y atención aparejadas al fenómeno migratorio entre los habitantes de Yucatán expuestos al mismo, en su mayoría procedentes del interior del estado y adscritos al pueblo maya.

Cuando se habla de salud se parte de una visión compleja, holística y multicausal, en la que los individuos se encuentran insertos en una cultura, sociedad y tiempo histórico que los determinan. Por lo tanto, resulta infructuoso tratar de garantizar la salud sin comprender las diferentes dimensiones que la determinan: cultural, económica, psicológica y comunitaria. Sin duda, las políticas públicas enfocadas a combatir el $\mathrm{VIH} /$ sida chocarán irremediablemente contra una gran barrera si se pierde de vista esta concepción compleja, holística y multicausal de la salud, dejando de lado los significados, valores, percepciones y prácticas que determinada población tiene sobre su cuerpo, la vida en pareja, su sexualidad, la enfermedad, así como las maneras tradicionales y contemporáneas en las que cuidan de su salud y la de sus familias.

En este sentido, el presente artículo expone los avances de investigación del proyecto "Prevalencia del VIH/sida y factores socio culturales asociados, para el desarrollo de estrategias de prevención entre migrantes mayas yucatecos" (Quintal, Vera, Paredes y Marín, 2012) desarrollado por un grupo de investigadoras adscritas al Centro de Investigaciones Regionales "Dr. Hideyo Noguchi" de la Universidad Autónoma de Yucatán. El proyecto estuvo dividido en dos etapas. El objetivo de la primera, realizada entre enero del 2012 y junio del 2013, fue realizar un diagnóstico mixto (cuantitativo y cualitativo) para identificar los factores de vulnerabilidad de tipo sociocultural, étnicos y de género asociados a la potencial adquisición del VIH/sida entre hombres migrantes mayas y las mujeres parejas de migrantes que los esperan en las comunidades de origen (ver Quintal y Vera, 2014). La información obtenida en la primera etapa sirvió como insumo para, durante la etapa dos, desarrollar estrategias y materiales educativos de prevención sobre $\mathrm{VIH} /$ sida con un enfoque intercultural, de género y desde el marco de los Derechos Humanos. Los escenarios de investigación de ambas etapas fueron los municipios de Chacsinkín y Tahdziú, ubicados al sur del estado.

En las siguientes páginas se ahonda en el análisis de los datos cualitativos obtenidos de las entrevistas en profundidad que se realizaron con 17 mujeres mayas parejas de migrantes, ${ }^{1}$ con el objetivo de explorar sus sistemas de creen-

\footnotetext{
${ }^{1}$ Si bien la investigación también abarcó, en igual medida, el trabajo con hombres migrantes y personal de atención a la salud de las clínicas locales, como actores centrales en la comprensión de la
} 
cias, significados y prácticas alrededor de las relaciones de género, la sexualidad y el VIH/sida. El análisis de esta información permitió identificar y comprender cuáles de estas dimensiones configuran escenarios de vulnerabilidad asociados a la potencial adquisición del $\mathrm{VIH} / \mathrm{sida}$ entre estas mujeres, y qué tipo de lineamientos se deben incorporar en las políticas públicas dirigidas a la prevención, tanto primaria como secundaria.

En primer lugar se dedica una sección al análisis de la intersección de dos conceptos claves en este trabajo: la vulnerabilidad social y el género. Se sostiene que existe una vulnerabilidad social propia de las mujeres y distinta a la de los hombres, que además es acumulativa en función de la edad, la clase social, el nivel educativo y la etnia a la que se pertenece entre otros factores; vulnerabilidad que deja a las mujeres en situación de indefensión para el control de su salud sexual y reproductiva. En el segundo apartado, caracterizamos brevemente el contexto de estudio y a las mujeres que participaron en la investigación. Saber quiénes son es esencial para aproximarnos a identificar algunos de los elementos sociodemográficos y económicos que contribuyen a construir la vulnerabilidad social y de género de estas mujeres ante el $\mathrm{VIH} / \mathrm{sida}$, dentro de los escenarios migratorios investigados. El tercer, cuarto y quinto apartados están dedicados a explorar una amplia serie de datos cualitativos referentes a los significados y prácticas asociados a la sexualidad y la vida en pareja, su educación sexual inicial, su acceso a la información y los significados y prácticas en torno al VIH/sida, mientras que el sexto ahonda en su percepción subjetiva del riesgo asociados a la díada migración-VIH/sida, desde su posición como parejas de migrantes, así como en las estrategias de autocuidado que ponen en marcha acorde a dichas percepciones.

En las reflexiones finales se busca entretejer los diferentes aspectos de lo que aquí llamamos "vulnerabilidad social de género", como una dimensión transversal que cruza otros elementos de la vulnerabilidad social y cultural al VIH/sida. Asimismo, las conclusiones se orientan a repensar qué estrategias parecen las más viables para incorporar en las políticas públicas y programas de acción dirigidos a la prevención y atención del $\mathrm{VIH} /$ sida entre las mujeres parejas de migrantes de este tipo de comunidades.

\section{Vulnerabilidad social y género: entrecruzamientos en la adquisición del VIH/sida}

Desde que apareció la epidemia del VIH/sida presenciamos una "evolución conceptual" en la forma de caracterizar la enfermedad: en primer lugar se usó la noción de "grupos de riesgo", para luego referirse a las "prácticas de riesgo" de

problemática, la abundancia de datos y la necesidad de cumplir con los criterios de la revista respecto a la extensión de las contribuciones hicieron necesario recortar el sujeto de análisis para este artículo. 
ciertos individuos. La visión de análisis centrada en el "riesgo" sólo lograba culpar a los portadores del virus de su propia condición, justificando los fracasos de un modelo de prevención basado solamente en ofrecer información, sin comprender que dichos comportamientos están condicionados por desigualdades sociales como las de género, etnia, edad, preferencia sexual o clase social. De esta crítica nace la idea de hablar de "situaciones y contextos de riesgo" o "condiciones sociales del riesgo", lo que posteriormente da lugar al concepto de vulnerabilidad (Herrera y Campero, 2002: 556).

En este trabajo se retoma el concepto de vulnerabilidad para referirse a las situaciones de inseguridad y desamparo que experimentan comunidades, familias e individuos en sus condiciones de vida a consecuencia de los impactos que provoca algún evento social o económico de carácter traumático. Una situación de vulnerabilidad tiene una serie de componentes estructurales determinantes, pero el concepto hace referencia al manejo de recursos y estrategias que pueden utilizar los sujetos para enfrentar los efectos de dicho evento (Pizarro, 2001). A diferencia del concepto de riesgo, la visión de la vulnerabilidad nos acerca a analizar el impacto de una serie de factores estructurales - políticos, sociales, históricos, culturales y económicos-que tienen impacto en el comportamiento y la toma de decisiones a nivel individual. La vulnerabilidad es siempre un indicador de inequidad y desigualdad social, donde el sujeto se enfrenta a una serie de limitaciones para tener control de su propia condición, y por lo tanto exige respuestas en el ámbito de la estructura social y política (Herrera y Campero, 2002: 556).

La epidemiología convencional se fundamenta mucho más en la idea de riesgo, pues se centra en analizar una serie de comportamientos y prácticas de carácter individual y monocausal, donde la enfermedad ocurre en un contexto social, estático y atemporal (Mann, 1996). En contraste, la epidemiologia crítica e intercultural hace hincapié en los procesos de salud-enfermedad-atención desde una perspectiva multicausal, dinámica, histórica, política y culturalmente situada (Breilh, 2003), donde más que el riesgo individual importa comprender las condiciones sociales de vulnerabilidad presentes en la conformación y distribución de las enfermedades entre la población en general, y el cuidado de la salud de un individuo particular. Desde este enfoque, la díada salud-enfermedad está condicionada por situaciones de marginación, pobreza, falta de acceso a la educación y a los servicios de salud, las relaciones de género, la organización social y los valores y creencias que dominan en un determinado grupo social.

En el caso del VIH/sida, actualmente existen elementos para considerar que en la última década esta enfermedad se ha convertido en un nuevo padecimiento de los pobres del denominado Tercer Mundo (Pedrosa, 2004: 151-152). Ya desde el Informe sobre la epidemia mundial del Sida (ONUSIDA, 2008) se afirmaba que la epidemia continuaba en expansión debido a que los gobiernos no estaban tratando de eliminar eficazmente las condiciones sociales que aumentan la vulnerabilidad asociados al Virus de Inmuno Deficiencia Humana (VIH). En dicho informe se 
hace mención de algunos factores que requerían atención urgente como son: la desigualdad de género, la discriminación, el estigma y la marginación social. Asimismo, se señalaba que cuando no se atienden estos factores se configuran escenarios propicios para engendrar vulnerabilidades múltiples, en los que las campañas de prevención chocan con grandes obstáculos. Tal es el caso de los programas y acciones de prevención del VIH/sida entre mujeres, que aunque contemplan el acceso a la información y a los artículos básicos para evitar la trasmisión (por ejemplo, preservativos), fracasan, pues no inciden en la transformación de las normas y mandatos de género que dictan un papel desigual y pasivo para las mujeres en la toma de decisiones, lo que socava su autonomía y las expone a la coacción sexual, la imposibilidad de negociación del uso del preservativo con sus parejas o la elección de la abstinencia sexual cuando así lo desean.

Por lo anterior, es central que siempre se incorpore al análisis de la vulnerabilidad la perspectiva de género y que se contemple la participación de los hombres en todas las campañas orientadas al cambio de significados y prácticas asociados a la sexualidad. Los mandatos tradicionales de género no sólo vulneran a las mujeres, también a los hombres. El modelo de masculinidad hegemónico exige que los hombres sean duros, agresivos, sexualmente dominantes y que asuman riesgos como el tener un elevado número de parejas sexuales, el consumo de drogas o alcohol y la negativa a buscar y recibir atención sanitaria, lo que con frecuencia los expone a la adquisición de diversas enfermedades e Infecciones de Transmisión Sexual (ITS), como el VIH/sida (De Keijzer, 1997; 2006).

Sin embargo, el grado de vulnerabilidad es diferente para hombres y mujeres (vulnerabilidades de género) pues la situación en la que se encuentra cada uno varía en lo biológico, social, económico y cultural. Así por ejemplo, en lo biológico las mujeres son de dos a cuatro veces más vulnerables a contraer el VIH, debido a que su zona de exposición al virus durante la relación sexual es de mayor superficie, y porque la carga viral es mayor en el semen que en los fluidos vaginales.

Por otra parte, la vulnerabilidad cultural tiene su base en las construcciones sociales de género dominantes en Occidente que marcan claras diferencias entre hombres y mujeres en lo relativo al acceso, ejercicio y control del poder y los recursos (económicos, sociales, legales, entre otros).

La vulnerabilidad social de las mujeres se construye y fortalece con la existencia de las brechas de género en términos de acceso a la educación, a la información, a la salud y al empleo digno, que cuando están presentes generan relaciones de sumisión y dependencia hacia los hombres. A esto se pueden sumar otras desigualdades sociales como pobreza, marginación o discriminación hacia determinados grupos, quedando las mujeres como el sector más vulnerable entre los vulnerables, cuando están presentes situaciones como el consumo de drogas, el trabajo sexual, ser parejas de hombres con prácticas de riesgo o VIH positivos, mujeres abusadas, migrantes o parejas de migrantes. En estos casos se puede hablar de situaciones de "vulnerabilidad acumulada" (Herrera y Campero, 2002: 557). 
A continuación se exploran varias dimensiones que caracterizan el contexto de vulnerabilidad de las mujeres de Tahdziú y Chacsinkín, su percepción de estar en un situación de riesgo asociada a la potencial adquisición de $\mathrm{VIH} / \mathrm{sida}$ al ser parejas de migrantes, así como la exploración de estrategias —o ausencia de ellas- que manejan para el autocuidado de su salud sexual y reproductiva.

\section{Sobre el contexto de investigación y las participantes}

El sujeto en el que centramos nuestra mirada fueron las mujeres mayas parejas de hombres que emigran semanal o quincenalmente desde dos comunidades ubicadas al sur del estado de Yucatán: Chacsinkín y Tadhziú, hacia Mérida, Cancún o la Riviera Maya; destinos que se encuentran a casi tres horas de sus localidades de origen.

De acuerdo con el Informe de pobreza y evaluación en el estado de Yucatán 2012, realizado por el Consejo Nacional de Evaluación de la Política de Desarrollo (CONEVAL, 2012) tanto Chacsinkín como Tahdziú se encuentran entre los cinco municipios con mayor porcentaje de su población en situación de pobreza del estado: $89.4 \%$ para el primero y $91.7 \%$ para el segundo. Esta circunstancia ha propiciado que sus habitantes se vean en la necesidad de buscar alternativas de subsistencia económica a través de la migración, que se ha vuelto una estrategia de sobrevivencia para cubrir necesidades de alimentación, vivienda, escuela y salud en las familias de ambos municipios.

Asimismo, en los dos municipios investigados predomina la población mayahablante. En Chacsinkín, con 2555 habitantes el $95.6 \%$ es mayahablante y en Tadhziú, de 4447 habitantes el 99.94\% habla maya (INEGI, 2010). Sin embargo, aunque no son sinónimos, en Yucatán etnicidad y pobreza conforman un binomio que las políticas públicas no han logrado desarticular (Ruz, 2006).

Las familias de las mujeres participantes en este estudio viven y se adaptan a la dinámica pendular de la migración regional. A diferencia de los casos de migrantes internacionales - donde los maridos se ausentan de sus comunidades por varios meses o años, situación que introduce variantes en las relaciones de género que se establecen dentro de la familia (Quintal, 2011)—, aquí el tipo de dinámica migratoria coadyuva a que las mujeres conserven su papel de género y relaciones familiares más o menos intactas. Es decir, no adquieren nuevos papeles o espacios de empoderamiento en la comunidad o el ejido, sino que se refuerza su dependencia a la pareja, la cual provee el ingreso familiar cada semana o quincena que retorna desde su destino migratorio a su comunidad de origen.

La dependencia económica de las mujeres hacia sus parejas constituye un primer indicador de vulnerabilidad social, pues las entrevistadas no tienen un empleo que les permita contar con un ingreso permanente para sostenerse de manera autónoma. Al momento de la investigación todas se dedicaban de forma preponderante a las labores domésticas, sólo algunas de ellas desarrollaban una 
actividad económica informal y remunerada desde su hogar, como el urdido de hamacas o la costura.

El acceso a la educación y los servicios de salud representan otros elementos estructurales de vulnerabilidad para las mujeres mayas parejas de migrantes. En este contexto es común que aquellas que acceden al ámbito educativo deserten antes de siquiera concluir la primaria. Menos de la mitad de las entrevistadas ingresó a la secundaria, aunque sin concluirla Estos datos destacan la vulnerabilidad en la que se colocan las mujeres en cuestión, ya que como sostiene el INEGI (2010: 123) "la tasa de analfabetismo es un indicador básico relacionado con el bienestar de una población". No obstante, el problema de la deserción escolar, tanto en Tadhziú como en Chacsinkín, trasciende al grupo de mujeres, es un problema estructural que alcanza a ambos sexos y que se agudiza en el bachillerato, que sólo logra concluir menos del 1\% de estas poblaciones (INEGI, 2010).

Todas las mujeres hablan y entienden - aunque no siempre leen, ni escribenel idioma maya, ya que es su lengua materna. Algunas son bilingües en distinto grado, que va desde las que entienden el español, pero prefieren responder en maya, hasta las que entienden y se expresan sin dificultad en maya o español según lo requieran. También hubo mujeres monolinguies, que sólo se comunican en maya. Por ello, en esta investigación se incorporó y capacitó a tres mujeres mayahablantes para que fungieran como traductoras en la relación entre entrevistadoras y entrevistadas, para un mejor desarrollo de las entrevistas en profundidad realizadas.

Respecto a los servicios de salud, en las dos localidades se practica de forma importante la medicina tradicional maya, caracterizada por la presencia de parteras/sobadoras, curanderos, quiroprácticos (hueseros) o sacerdotes mayas. Además, tanto en Tadhziú como en Chacsinkín existen centros de salud administrados por el gobierno estatal, al que reportaron tener acceso todas las entrevistadas mediante la figura del "Seguro Popular", implementado por el Gobierno Federal. Hay que añadir que el $50 \%$ de las mujeres entrevistadas contaba con el apoyo del Programa Oportunidades, ${ }^{2}$ programa gubernamental de tipo asistencialista que conlleva la obligación de cumplir con revisiones médicas regulares y asistir a talleres informativos y preventivos sobre diversas temáticas de salud y reproducción en los centros de salud de la comunidad, a cambio de recibir un subsidio económico o beca que el Estado otorga por cada hijo que asiste a la escuela.

La población tiene acceso a la salud en el nivel básico, pero para emergencias, casos más complejos o estudios especializados, los/as derechohabientes tienen que dejar su pueblo y desplazarse al municipio más cercano, que es Peto, o la ciudad de Mérida. Esto a pesar de las circunstancias que ello conlleva, como la falta de medios de transporte eficientes y el riesgo de no ser atendidos cuando finalmente llegan a los servicios de salud. A ello hay que agregar la insensibilidad del per-

\footnotetext{
${ }^{2}$ Programa de corte asistencialista que el gobierno mexicano diseñó y puso en marcha en el 2002 para abatir la pobreza en las comunidades más marginadas del país, buscando mejorar su nutrición, salud y educación.
} 
sonal de salud en Mérida respecto a las dificultades que tienen que enfrentar las derechohabientes de las comunidades mayas del interior del estado para llegar hasta los servicios de salud en dicha ciudad:

Entrevistadora: ¿Por qué dejaste de ir a tus chequeos al hospital O’Horan de Mérida? Entrevistada: Porque me fastidió sólo ir y que no me atiendan. En octubre fui y me rechazó la enfermera porque llegué tarde, pero ¿cómo voy a poder llegar a la hora que me citan?, si aquí pasa el camión a las 4 de la madrugada y a las 7 de la mañana hay que estar en Mérida. Voy a pedir ayuda en el $\mathrm{CDI}^{3}$ de Peto, nos llevan, nos quitamos de ahí como a las 5, pero cuando vayan así en el periférico de Mérida hay mucho tráfico y no podemos llegar a las 7 . Llegué a las 8 , ya mero daban las 8 y me dijo la enfermera del O'Horan que ya no me atendería, que mi cita era a las 7, o sea que aunque llegué, me rechazó (Norma, 20 años).

La insensibilidad y ausencia de empatía de las instituciones de salud y personal médico hacia las circunstancias que conlleva el acceso a los servicios de salud para los habitantes del interior del estado, se traduce en castigos indirectos como la no atención por llegar tarde, de acuerdo al testimonio de Norma, pero también se refleja en la falta de personal de salud mayahablante y conocedor de la cultura maya, capaz de captar las necesidades de esta población y establecer un diálogo intercultural entre el sistema institucional y el tradicional, que permita comprender mejor la dimensión cultural de la salud, en la que juega un papel importante la atención que la población recibe por parte de yerbateros y parteras.

Para finalizar con lo relativo a la información del contexto de investigación y las participantes, en las tablas 1 y 2 se presentan algunos datos que permiten caracterizar el perfil sociodemográfico de las 17 mujeres mayas parejas de migrantes que fueron entrevistadas para este estudio:

En términos generales se puede observar que el mayor grado de escolaridad de las mujeres mayas es secundaria completa, nivel que han alcanzado 8 de 17 entrevistadas. En el resto predomina primaria y primaria incompleta. Asimismo, es notorio que las de mayor edad tienen menor escolaridad y más número de hijos. Ésta es una regla en diferentes contextos de México. Otro aspecto que es llamativo es el hecho de que casi el 50\% de ellas realiza actividades económicas desde su hogar que les generan un ingreso que termina siendo de mucho apoyo en el gasto familiar.

\section{Significados y prácticas asociados a la sexualidad}

En torno al escenario y las mujeres participantes en el estudio, se despliega una serie de significados y prácticas de la vida en pareja, la sexualidad, la reproduc-

\footnotetext{
${ }^{3}$ Se refiere a los Centros Coordinadores de la Comisión Nacional para el Desarrollo de los Pueblos Indígenas.
} 


\begin{tabular}{|c|c|c|c|c|c|c|c|}
\hline $\begin{array}{l}\text { Mujeres de } \\
\text { Chacsinkín }\end{array}$ & Edad & $\begin{array}{c}\text { Años de } \\
\text { vida en } \\
\text { pareja }\end{array}$ & $\begin{array}{l}\text { Número } \\
\text { de hijos }\end{array}$ & Ocupación & Escolaridad & Religión & $\begin{array}{c}\text { Destino } \\
\text { migratorio } \\
\text { de la pareja }\end{array}$ \\
\hline Helena & 39 & 26 & 7 & $\begin{array}{c}\text { Ama de casa, } \\
\text { urdido de } \\
\text { hamacas }\end{array}$ & $\begin{array}{l}\text { Primaria } \\
\text { incompleta }\end{array}$ & Católica & Mérida, Yuc. \\
\hline Jimena & 35 & 18 & 3 & $\begin{array}{c}\text { Ama de casa, } \\
\text { urdido de } \\
\text { hamacas y } \\
\text { pintura de } \\
\text { hipiles }\end{array}$ & $\begin{array}{l}\text { Secundaria } \\
\text { completa }\end{array}$ & Católica & Cancún, Q. Roo \\
\hline Gabriela & 21 & 1.5 & 1 & Ama de casa & $\begin{array}{l}\text { Primaria } \\
\text { completa }\end{array}$ & Cristiana & Mérida, Yuc. \\
\hline Adela & 40 & 20 & 3 & $\begin{array}{c}\text { Ama de casa, } \\
\text { urdido de } \\
\text { hamacas }\end{array}$ & $\begin{array}{l}\text { Secundaria } \\
\text { completa }\end{array}$ & Católica & Mérida, Yuc. \\
\hline Concepción & 31 & 14 & 4 & Ama de casa & $\begin{array}{l}\text { Primaria } \\
\text { completa }\end{array}$ & Católica & $\begin{array}{c}\text { Playa del } \\
\text { Carmen, Q. Roo }\end{array}$ \\
\hline Norma & 20 & 4 & 1 & Ama de casa & $\begin{array}{l}\text { Secundaria } \\
\text { completa }\end{array}$ & Católica & $\begin{array}{c}\text { Cancún y Playa } \\
\text { del Carmen, } \\
\text { Q. Roo. }\end{array}$ \\
\hline Hortensia & 51 & 34 & 5 & $\begin{array}{c}\text { Ama de casa, } \\
\text { urdido de } \\
\text { hamacas y } \\
\text { bordadora }\end{array}$ & $\begin{array}{l}\text { Primaria } \\
\text { completa }\end{array}$ & Católica & $\begin{array}{c}\text { Playa del } \\
\text { Carmen, Q. Roo }\end{array}$ \\
\hline Mónica & 21 & 2 & 1 & $\begin{array}{l}\text { Ama de casa } \\
\text { y bordadora }\end{array}$ & $\begin{array}{l}\text { Secundaria } \\
\text { completa }\end{array}$ & Presbiteriana & Mérida, Yuc. \\
\hline Federica & 34 & 19 & 4 & $\begin{array}{c}\text { Ama de casa, } \\
\text { urdido de } \\
\text { hamacas }\end{array}$ & $\begin{array}{l}\text { Primaria } \\
\text { completa }\end{array}$ & Católica & $\begin{array}{l}\text { Mérida, Yuc. } \\
\text { Cancún y Playa } \\
\text { del Carmen, } \\
\text { Q. Roo. } \\
\text { Escárcega, } \\
\text { Camp. }\end{array}$ \\
\hline
\end{tabular}

TABLA 1. Datos sociodemográficos de mujeres entrevistadas en Chacsinkín.

Fuente: Entrevistas en profundidad del Diagnóstico Cualitativo del Proyecto FOMIX-CONACYT

(169279) "Prevalencia del VIH/sida y factores socio culturales asociados, para el desarrollo de estrategias de prevención entre migrantes mayas yucatecos"

(Quintal, Vera, Paredes y Marín, 2012). 


\begin{tabular}{|c|c|c|c|c|c|c|c|}
\hline $\begin{array}{c}\text { Mujeres de } \\
\text { Tahdziú }\end{array}$ & Edad & $\begin{array}{c}\text { Años } \\
\text { de vida } \\
\text { en } \\
\text { pareja }\end{array}$ & $\begin{array}{c}\text { Número } \\
\text { de hijos }\end{array}$ & Ocupación & Escolaridad & Religión & $\begin{array}{c}\text { Destino } \\
\text { migratorio de } \\
\text { la pareja }\end{array}$ \\
\hline Juliana & 33 & 12 & 3 & Ama de casa & $\begin{array}{c}\text { Primaria, } \\
4^{\circ} \text { año }\end{array}$ & Católica & Mérida, Yuc. \\
\hline Carolina & 23 & 3 & 0 & $\begin{array}{c}\text { Ama de casa } \\
\text { Costurera }\end{array}$ & $\begin{array}{c}\text { Secundaria } \\
\text { completa }\end{array}$ & Católica & $\begin{array}{c}\text { Mérida, Yuc. } \\
\text { Playa del } \\
\text { Carmen, Q. Roo. }\end{array}$ \\
\hline Daniela & 42 & 25 & 8 & Ama de casa & $\begin{array}{c}\text { Primaria, } \\
4^{\circ} \text { año }\end{array}$ & Católica & $\begin{array}{c}\text { Mérida, Yuc. } \\
\text { Playa del } \\
\text { Carmen, Q. Roo. }\end{array}$ \\
\hline Carmela & 30 & 13 & 3 & $\begin{array}{c}\text { Vendedora de } \\
\text { Catálogo }\end{array}$ & $\begin{array}{c}\text { Primaria } \\
\text { completa }\end{array}$ & Cristiana / & $\begin{array}{c}\text { Mérida, Yuc. } \\
\text { Cancún y } \\
\text { Cozumel, Q. } \\
\text { Roo. }\end{array}$ \\
\hline Amanda & 58 & 42 & 11 & Ama de casa & Sin estudios & Católica & California, EUA. \\
\hline Juana & 29 & 6 & 3 & Ama de casa & $\begin{array}{c}\text { Secundaria } \\
\text { completa }\end{array}$ & Católica & Mérida, Yuc. \\
\hline Dalila & 21 & 6 & 2 & Ama de casa & $\begin{array}{c}\text { Secundaria } \\
\text { completa }\end{array}$ & Católica & $\begin{array}{c}\text { Playa del } \\
\text { Carmen, Q. Roo. }\end{array}$ \\
\hline
\end{tabular}

TABla 2. Datos sociodemográficos de mujeres entrevistadas en Tahdziú. Fuente: Entrevistas en profundidad del Diagnóstico Cualitativo del Proyecto FOMIX-CONACYT (169279) "Prevalencia del VIH/sida y factores socio culturales asociados, para el desarrollo de estrategias de prevención entre migrantes mayas yucatecos"

(Quintal, Vera, Paredes y Marín, 2012). 
ción y la salud, que al anclarse dentro de las condiciones materiales de carencia del contexto investigado se configuran como parte de la vulnerabilidad social y de género de estas mujeres.

En lo que se refiere a la construcción de género, históricamente y por diversos motivos, se han desarrollado estrategias para controlar las capacidades reproductivas, productivas y sexuales de las mujeres. Estas estrategias de dominación se asientan en una serie de valores y prácticas en torno al cuerpo y la sexualidad prescritas diferencialmente, según se trate de cuerpos de hombres o de mujeres. Fernández (1993) se refiere a ello como el discurso de la doble moral, el cual no sólo es una forma de controlar los cuerpos, sino también un medio eficaz de controlar las conciencias, que deriva a su vez en un ejercicio desigual de autonomía y poder entre hombre y mujeres.

En el caso de las mujeres los mandatos de género incluyen: la virginidad antes del matrimonio, la pasividad, el no reconocimiento o expresión del deseo sexual, la obligación de complacer a la pareja más allá de su propia voluntad, la fidelidad y la procreación como principal motivo para ejercer la sexualidad. El apego a estos significados y prácticas puede volverse un gran obstáculo para promover una prevención eficaz ante la transmisión del VIH/sida (Herrera y Campero, 2002: 558).

En términos generales, y a partir de sus testimonios, las mujeres entrevistadas se pueden definir en conjunto como heterosexuales y monógamas, madres de familia y esposas que se tienen que hacer cargo del hogar y los hijos durante las intermitentes ausencias de sus parejas. Ninguna de las entrevistadas se concibe fuera de este modelo socialmente impuesto, y aunque abierta o sutilmente reconocen que les resulta duro, pareciera que no tienen opción. En el contexto en el que viven, la maternidad no es una elección sino un destino que las legitima ante la comunidad, la familia y la propia pareja:

Me gusta ser mamá porque aquí en el pueblo si una no se hace mamá empiezan a decir que es machorra, que no puede tener hijos, que no sé qué... (Gabriela, 21 años).

Muchas mujeres actualmente no quieren tener hijos, pero los tienen, se casan muy pronto, a veces se las roban los novios cuando todavía están estudiando la secundaria. Al poco tiempo que ya viven con él, quedan embarazadas, a veces desde los 14 años. Los hombres tienen vicios y la vida de esas pobres mujeres es muy dura (Amanda, 58 años).

Los anteriores testimonios son representativos de lo que ocurre en este contexto, en el que la vida en pareja y la sexualidad están centradas en la reproducción, por lo que para muchas de ellas no tiene sentido la planificación familiar, al menos al principio de la vida conyugal. Posteriormente, para evitar embarazos no deseados, la mayoría recurre al uso de anticonceptivos orales o inyectados que se les proveen en los centros de salud locales. Quién no usa anticonceptivos depende de que "su pareja la cuide": 
ENTREVISTADORA: ¿Cómo te cuidas tú? ¿Ahorita llevas planificación familiar?

EnTREVISTADA: Sí, pero ya lo dejé, ahorita él me está cuidando.

ENTREVISTADORA: ¿Y cómo te cuida?

Entrevistada: Pues... pues... cuando viene su líquido lo saca afuera y así no me embarazo (Amanda, 58 años).

Otras mujeres se cuidan estando atentas a su ciclo hormonal para evitar embarazarse, lo que técnicamente, como es sabido, se llama método de calendario o ritmo Ogino-Knaus. Al final, en la mayoría de los testimonios, son las mujeres las principales responsables de evitar los embarazos, pese a los efectos que la anticoncepción tiene sobre su salud y cuerpo:

Mi esposo dice que ya no me embarace, ya tengo 42 años, él no quiere usar condón ni nada, así que yo soy la que me tengo que cuidar (Daniela, 42 años, traducido del maya; el énfasis es nuestro).

He visto mujeres que cuando comienzan a planificar se ensanchan sus caderas, a otras les crece mucho la barriga. Unas de mis nueras era muy delgada, no parecía haber tenido hijos, ahora ya engordó mucho y tiene la espalda y cadera anchas por lo que le inyectan para que no tenga más hijos (Adela, 40 años).

En otras investigaciones en torno a la migración y las relaciones de género (D’Aubeterre-Buznego, 2000; Flores, 2013; Leyva y Caballero, 2009) se han rescatado múltiples testimonios que apuntan a mostrar que la falta de planificación familiar se debe a una estrategia del varón para controlar la vida sexual de su pareja cuando él está lejos de la comunidad por motivos de trabajo. Si su pareja se opera o usa anticonceptivos podría sostener relaciones sexuales con otros hombres del pueblo, sin el riesgo de embarazarse, lo que les daría más libertad a las mujeres y menos poder a los hombres sobre el cuerpo de su pareja y sus familias.

Mi esposo se dedicaba [a trabajar] de albañil. Cuando me casé me empezó a maltratar, estuvo celoso tras de mí y ya no se iba ni a trabajar, me cuidaba y decía que le daba miedo que otra persona venga conmigo, y cosas así dice. Yo trataba de hacer que razone, pero nunca lo entendió. No le gusta lo de la planificación para no tener varios hijos y lo que él me dice es que está mejor así estar embarazada, que así ningún hombre puede venir conmigo, me dijo toda clase de chucherías (Dalila, 21 años).

Sobre esta relación de poder se construyen muchos miedos y mitos relacionados con el uso de anticonceptivos, especialmente alrededor del condón. Ninguna de las entrevistadas ha usado el condón con su pareja como método de anticoncepción o de cuidado de su salud sexual. Esto se asocia principalmente con la negativa de los hombres a utilizarlo, bajo una serie de diversos argumentos entre los que destacan: decirle a sus parejas que ellos como hombres no lo saben usar, que no van a sentir el mismo placer, que va a fallar, que no es necesario su uso porque sólo tiene relaciones sexuales con ella o simplemente que no quieren utilizarlo y eso no está a discusión: 
En el Seguro Social te muestran el condón, dicen que lo deben usar los hombres para prevenir, pero mi marido me dice a mí "¿Para qué me sirve?, al rato se zafa y se queda dentro de ti, no te va a gustar, sin condón vas a sentir más rico". Pero sí lo conocí, parece bola o globo [...], me enseñaron la planificación y a mí no gusta eso porque en ocasiones las mujeres se enferman, a veces está uno sano y cuando planifica se enferma (Amanda, 58 años).

Entrevistadora: Aquí en el pueblo ¿usan el condón?

EnTREVISTADA: La verdad no sé, mi esposo nunca lo quiso usar. Una vez fuimos con el doctor y se lo dio, yo le dije: “¿Cómo se usa?", "No lo sé” me respondió. "Además —dice—, pues sólo estoy contigo ¿Para qué voy a usar algo así?”, pues luego pensé que tiene razón. Para qué, si sólo está conmigo (Federica, 34 años).

En el contexto de la presente investigación, el tema del uso o no del condón y las razones y motivaciones asociadas a ello cobra una particular relevancia, ya que hasta ahora su correcta utilización es la única forma de prevenir la adquisición del VIH por efecto del contacto sexual. En este sentido, la ausencia de su empleo entre las mujeres parejas de migrantes las ubica en un contexto de alta vulnerabilidad, ya que propicia un escenario para la realización de prácticas sexuales de riesgo, que ponen en peligro la salud, bienestar y calidad de vida de estas mujeres.

Aunque la epidemia sigue siendo predominantemente masculina, pues el $82.5 \%$ de las personas diagnosticadas en Yucatán son hombres, en la última década se ha observado una tendencia a su feminización (Secretaría de Salud de Yucatán, SSY, 2012). Así tenemos que, mientras que en 1984 la proporción de casos hombremujer era 6.1 a 1, en 2007 había pasado a ser de 3.5 a 1 (Magis et al., 2008: 60), es decir la brecha se ha ido reduciendo significativamente. Las cifras son claras y apuntan a que el VIH/sida se ha ido tornando cada vez más femenino, más joven y más pobre (CENSIDA, 2013). Esta tríada de condiciones, que configuran un escenario de vulnerabilidades acumulativas (Mora, 2002), está presente en muchas de las mujeres parejas de migrantes que permanecen en las comunidades de origen y que viven en contextos de carencia de recursos materiales, sociales y falta de acceso a derechos fundamentales (como la educación). En este sentido, la condición migratoria de sus parejas se vuelve una dimensión que acentúa y agrava esta vulnerabilidad (Leyva y Caballero, 2009; Flores-Palacios, 2013; Quintal y Vera, 2014).

La vulnerabilidad de género en el caso de las mujeres, se configura a partir de la exposición a relaciones de sometimiento y subordinación, es decir de violencia material y simbólica, que debilitan sus recursos y capacidades, y por ende su autonomía y toma de decisiones, dejándolas en un estado de indefensión que les dificulta establecer acuerdos para sostener cuidados en su salud en general, y en sus prácticas sexuales en lo particular. 


\section{Sobre la educación sexual entre las mujeres mayas}

Cabe recordar, de inicio, que la "educación sexual" no sólo se refiere al acceso a información sobre anatomía, fisiología, reproducción, planificación familiar y temas relacionados, sino que abarca un aprendizaje y vivencia del propio cuerpo y el de los demás, una serie de prácticas de la sexualidad e incluso la socialización de género, que inicia en la niñez siendo la familia el principal agente educador (Rubio, 1994).

El análisis de los testimonios sobre la educación sexual que recibieron las mujeres durante la niñez y la adolescencia nos remite a una educación sexual muy limitada por tratarse de una temática tabú. Por lo general, la primera menstruación era el catalizador para explicarles algunas cosas, y las niñas — sin siquiera comprender los procesos de cambio que afrontaban sus cuerpos- entendían que a partir de ese momento podían tener hijos si un hombre las "tocaba". Los hombres y el contacto con sus cuerpos se volvían repentinamente algo peligroso, pero muchas seguían desconociendo los detalles de cómo se entabla una relación sexual y cómo se gestan los embarazos:

Nunca nos decían nada de la menstruación, cuando me pasó mi mamá dijo "Ahora ya estás grande, tienes que cuidarte. No te vayas a dejar que te besen por ningún chavito porque si no, puedes encargar"4 (Juliana, 33 años).

Para muchas, fue sólo hasta su primer encuentro sexual cuando supieron en qué consiste la dinámica básica del sexo. Fue en su vida en pareja donde fueron aprendiendo todo lo que saben sobre sexualidad, generalmente guiadas por sus esposos:

ENTREVISTADORA: ¿cómo esperabas que fuera tu vida en pareja?

ENTREVISTADA: pues que sólo voy a lavar su ropa, y que me dijeran "Sólo compra así los bebés”, porque no sé cómo es, sólo me dicen que tienen que juntar el dinero para que vas a comprar en el hospital comunitario. Le digo a mi esposo, "¿Cuándo vamos a comprar al bebé?", le digo, "Cuando junte el dinero", pero no imaginé cómo se hacen los bebés.... Cuando ya me casé, me daba pena, como que quiero ir otra vez a mi casa (Mónica, 21 años).

EnTREVISTADORA: ¿Cuándo era tu novio alguna vez te propuso tener relaciones sexuales?

EnTREvistadA: No, sólo a veces cuando me decía “¿Quieres que yo te bese?” y yo le decía “¿Qué tal si salgo embarazada?”. Y él me dice "No, es otra cosa lo que hacen cuando se embarazan", pero no me dijo cómo es, sólo me dijo: "El beso y abrazo no hacen nada”. Él mismo me lo dijo, yo di la confianza también y empecé a besarme con él, a abrazarlo, y vi que nada pasaba (Gabriela, 21 años).

Cuando me casé y entró la noche no sabía qué iba a pasar, yo creo que mi esposo sí lo sabía pero yo no, sólo estaba parada. Él me decía "iCoño! ¿por qué no

\footnotetext{
${ }^{4}$ Es decir, quedar embarazada.
} 
vienes a mi lado?" y yo sólo estaba parada y él estaba acostado y le digo "Es que tengo miedo" y yo sólo sentía ganas de llorar. Él me decía "Ven a mi lado", y yo no me animaba y ya mero amanecía. Hasta que él se levantó y como yo no iba, me jaloneó y me llevó a su hamaca porque yo no iba. Es que me daba mucha pena, no como ahora que las mujeres ya no tienen ni miedo [...] Antes no sabía uno nada... yo antes tenía miedo, ahora me entrego (Hortensia, 51 años, traducido del maya).

Así pues, estas mujeres aprendieron sobre su cuerpo sólo con base en la experiencia, no exenta de miedos, mitos y vacíos, en vez de información precisa. Destaca también el hecho de que una parte importante de conocimientos y experiencias sobre sexualidad sólo la adquieren una vez que inician su vida en pareja. Su iniciación sexual, sobre todo la de las mujeres de mayor edad, se dio en un escenario marcado por la ignorancia, el miedo y la fragilidad, desde el que no existe espacio para el autoconocimiento o autoexploración. La estimulación placentera de sus cuerpos sólo está permitida y es bien vista si viene de las manos de otro, de un hombre, léase el esposo. El autoerotismo como fuente de placer, a la vez que de poder, les es expropiado desde pequeñas a las mujeres, creando así las condiciones para lo que Fernández (1993) ha nombrado como "la cliteridectomía simbólica”. Ésta representa uno de los ejemplos más elocuentes de la violencia simbólica hacia las mujeres, que promueve su actitud pasiva en el terreno de lo erótico.

El tramo que las mujeres tendrán que atravesar desde la pasividad hacia la autonomía y responsabilidad de su sexualidad, autoerotismo y placer, implicará establecer nuevos vínculos, a la vez que vivir rupturas o deshacer mitos (Quintal, 2007). Sin duda, la carencia de información, la imposibilidad de tomar decisiones informadas y autónomas sobre sus propios cuerpos es la raíz de la condición de vulnerabilidad de estas mujeres mayas.

Para algunas de las mujeres entrevistadas, además de la familia y la pareja, la escuela y las pláticas y talleres que se brindan en los centro de salud de sus comunidades, en el marco del programa de gobierno Oportunidades, son otras fuentes de conocimiento sobre sexualidad. La información sobre ésta y acerca de la reproducción que reciben las mujeres que son beneficiarias de dicho programa proviene de talleres mensuales, con carácter de obligatorios. Las mujeres que no cuentan con tal apoyo también reciben orientación en el Centro de Salud, pero de manera más esporádica y sólo cuando la solicitan.

Varias de las entrevistadas se refirieron a dichos talleres y pláticas con aburrimiento o fastidio, remarcando el carácter obligatorio de su asistencia a los mismos, más que un genuino interés por informarse:

ENTREVISTADORA: ¿Ha estado en un curso sobre VIH?

EnTREvisTADA: Nos dan pláticas en la clínica, cada mes.

EnTREVISTADORA: ¿y le gusta ir a esas platicas o no le gusta?

EnTREvISTADA: Aunque no me guste, pero por obligación tengo que ir por mi Oportunidades que tengo. Pasan lista y si no fuiste, cuando llega tu dinero no te lo dan.... Sí 
entiendo lo que hablan en los talleres, pero me fastidia porque desde que llega una sólo eso te están diciendo. Eso ya lo escuche, además yo no ando haciendo pendejadas. Son personas que andan haciendo cosas, que con una vez que lo escuche... ahora si uno quiere hacer pendejadas, hace pendejadas. Es su vida de uno (Hortensia, 39 años).

La ausencia de interés por parte de las beneficiarias del programa Oportunidades en las mencionadas pláticas o talleres dirigidos a la prevención, plantea la necesidad de que se evalúe de forma seria y sistemática, el impacto de este programa no sólo a través de indicadores de tipo cuantitativo, como podrían ser el número de talleres impartidos o el porcentaje de mujeres que asisten a los mismos, sino también y prioritariamente sus componentes e impactos de tipo cualitativo. En este sentido, sería importante analizar la pertinencia y calidad de los temas, materiales y estrategias didácticas que se brindan en las clínicas comunitarias, así como la incorporación de criterios propios del modelo de atención intercultural en salud en las pláticas y talleres que se imparten a las mujeres mayas, de tal forma que se propicie un verdadero diálogo y espacio de aprendizaje entre las usuarias y los prestadores de salud.

Al respecto, se debe señalar que a partir de 2008 la Dirección General del Programa Oportunidades lanzó la "Estrategia de Fortalecimiento de Talleres Comunitarios”, con el objetivo de actualizar y reemplazar la lista de temáticas y materiales didácticos, así como fortalecer la metodología que el personal de salud emplea para la impartición de los talleres (ver Comisión Nacional de Protección Social en Salud, 2008). Sin embargo, muchos de estos paquetes didácticos nunca llegaron completos a las comunidades de estudio, pero más grave aún es que no tomaron en cuenta seriamente los factores interculturales y de vulnerabilidad social que están en la base de los problemas de salud que tratan, como son la desigualdad de género y los tabúes que perviven sobre sexualidad. En las entrevistas realizadas se manifestaron algunos de estos tabúes, se identificó que incluso ya siendo mujeres adultas las señoras no hablan de temas sexuales con su familia; sólo lo hacen, y en contadas ocasiones, con alguna hermana mayor o amiga muy cercana:

ENTREVISTADORA: y ahora cuando tienes dudas sobre algo ¿a quién acudes?

EntrevistadA: Voy al Centro de Salud, a veces con mi amiga Rosy. Con otras no, ni con mi cuñada, ni con mi suegra, ni con mi mamá, no se puede hablar de ello [...]. Con mi amiga sí, porque me cuenta todo y yo también a veces le cuento (Concepción, 31 años).

\section{Conocimientos, significados y prácticas en torno al VIH/sida}

Casi toda la información que las mujeres mayas participantes en esta investigación han recibido sobre el VIH/sida provino del personal de salud local. Para la mayoría de las mujeres el VIH/sida es un tema nuevo, del que han ido aprendiendo poco a poco: 
Ya tengo 33 años, pero cuando era más joven en la escuela no te decían eso, no lo escuchabas en la radio, no había información. Ya tenía a mis hijos cuando escuché que sí hay el sida [...]. Las cosas son así acá, son muy atrasadas, porque como estamos en el pueblo... (Juliana, 33 años, traducido del maya).

Sin embargo, todas han escuchado algo acerca del VIH/sida. De manera general lo relacionan con una enfermedad de transmisión sexual, aunque de manera específica puedan no tener claridad sobre las formas de trasmisión y prevención. Ante la pregunta de "¿Qué es el VIH/sida?" muchas lo asocian con la promiscuidad y la prostitución, y lo perciben como algo ajeno a su contexto inmediato:

ENTREVISTADORA: Oye Juana y ¿has escuchado hablar de la enfermedad del VIH/sida?

ENTREVISTADA: Sí, he escuchado [sobre] ella. El sida viene de esas mujeres que salen a trabajar, esas que venden su cuerpo. Aquí no hay (Juana, 29 años).

Se habla del sida como un problema que viene de fuera, fuertemente asociado con la migración. Por lo mismo, la mayoría de las entrevistadas cree que son los hombres quienes tienen mayor riesgo de contraer VIH, ya que salen del pueblo a trabajar. Ninguna afirma conocer personalmente a alguien que tenga dicha enfermedad en su pueblo:

He escuchado que el sida es por relaciones sexuales, uno se tiene que cuidar porque viene el marido con su esposa y se lo puede pegar... Aquí en el pueblo hay muchos hombres que trabajan en Mérida, pero gracias a Dios hasta ahorita ninguno ha contagiado a su esposa... No conozco a nadie con sida (Juliana, 33 años).

Prevalecen además muchos mitos respecto a las maneras de trasmisión y/o adquisición del VIH/sida, que van desde pensar que se puede adquirir con el mero contacto físico con un medio infectado (baños, agua, utensilios) hasta por medio de piquetes de mosquitos o besos en la boca:

EnTREVISTADORA: ¿Qué es lo que sabes del VIH/sida?

EnTREvistadA: Que te contagias, si te pica un mosquito así o si te cortas. Me dijeron también que si vas en la playa si estás reglando, sí te contagias.

EnTREVISTADORA: ¿Quién te lo dijo?

EntrevistadA: No me acuerdo quien, he escuchado eso en la escuela [...]. Los que salen a trabajar tienen más peligro de enfermarse porque ahí hay muchos mosquitos, hay muchas cosas así tiradas en las calles, aquí no. Como aquí pasan las señoras a barrer, porque si no han barrido su casa, les ponen tache cuando venga Oportunidades. ${ }^{5}$ Por eso pasa una señora a ver sus casas si están limpias (Norma, 20 años).

EnTREVISTADORA: ¿Tú sabes cómo una persona puede enfermarse de VIH/sida?

ENTREVISTADA: Si un mosquito pica a una persona enferma y luego te pica a ti. Tam-

${ }^{5}$ Es decir, el apoyo económico que otorga el programa. 
bién si usas las cucharas de alguien que tiene sida [o] si besas en la boca a alguien enfermo de sida te puede contagiar (Mónica, 21 años).

Respecto a los síntomas y signos, muy pocas entrevistadas creen que podrían identificarlos "porque nunca he visto a nadie con esa enfermedad". Sin embargo, la mayoría sabe que el VIH/sida se puede detectar mediante una prueba que se realiza en las clínicas y hospitales de manera gratuita, aunque ninguna de ellas ha acudido a solicitar esta prueba como parte de una rutina de autocuidado. A quienes se les ha realizado ha sido como parte de un procedimiento de rutina durante el embarazo. Es decir, hasta ahora en este contexto el diagnóstico depende enteramente de la decisión del personal de salud en turno. En este sentido, se vislumbra la necesidad de fomentar entre las mujeres mayas parejas de migrantes la realización de la prueba de detección de VIH al menos una vez al año, como parte de una rutina de autocuidado en salud. Consideramos que esta medida sería una importante estrategia de prevención secundaria, para aminorar el impacto que la epidemia del VIH puede llegar a tener en la vida de estas mujeres, insertas en contextos de vulnerabilidad.

Todas las mujeres han escuchado que el condón masculino es el principal medio para prevenir el VIH, pero ninguna lo usa de forma consistente con su pareja, además de que mostraron no saber usarlo correctamente:

Una vez me dieron el condón, pero me da miedo, porque no sé cómo se usa. Mmmm..., no sé cómo se usa eso. Sí nos enseñan en el centro de salud... Si tengo Oportunidades, pero sólo de verlo nada más no me gusta (Carmela, 30 años).

Entrevistadora: ¿y qué puedes hacer tú para que no te infectes de VIH/sida?

ENTREVISTADA: Pues de preferencia mucha protección, aunque como dice una señora ¿yo para que me protejo si no tiene sabor con condón? (risas). Claro que después no va a tener sabor tu vida si estás enferma, bueno eso es lo que yo siento y lo que pienso... Bueno, yo no uso protección porque es sólo mi marido y yo, pero si yo tuviera que tener otra pareja o quisiera tener otra pareja, prefiero ver que de verdad él use su condón para mi protección, aunque no sepa si tenga sida (Jimena, 35 años).

\section{Percepción de riesgo y estrategias de autocuidado}

Más allá de lo que nosotras podamos evaluar como condiciones de vulnerabilidad y prácticas de riesgo en esta población, nos interesó rescatar las miradas de las propias mujeres sobre su situación, y el tipo de estrategias que ponen en marcha para salvaguardar su salud, si es que toman alguna medida. Esto, como punto de partida para diseñar una política de prevención en materia de VIH, que en verdad pueda aproximarnos a las preocupaciones de estas mujeres y que no caiga una vez más en el discurso salubrista normativo y vacío de significados. 
Las mujeres mayas identificaron tres factores que desde su percepción aumentan la posibilidad de que una persona contraiga el VIH/sida: la emigración, el tipo de destino migratorio y la promiscuidad. En primer lugar todas coincidieron en que son los hombres quienes tienen más probabilidades de contraer una enfermedad de tipo sexual, porque son quienes salen del pueblo por motivos de trabajo. Para ellas, entre todos los migrantes, los que se van a los Estados Unidos son los más vulnerables, pues tienden a irse por periodos largos y mientras más tiempo estén fuera de la comunidad es más probable que "se busquen a otra mujer que los enferme". Esto refuerza la idea de que el VIH/sida es un problema que viene de afuera y en gran medida es ajeno al pueblo. Las mujeres reconocen que los hombres migrantes están en una situación de mayor riesgo, pero no alcanzan a percibir que ellas, al ser parejas de migrantes, también tienen más posibilidades de adquirir el VIH/sida si mantienen relaciones sexuales con ellos y sin protección. El no percibir el riesgo en lo individual puede deberse a dos creencias interconectadas entre sí. Por un lado, las mujeres destacaron: "sólo la gente promiscua se contagia". Por otra parte, en la medida que varias de ellas se autoadscriben como "fieles", "mujer de un solo hombre", se sienten protegidas de adquirir el VIH, pues creen en los preceptos del amor romántico (Giddens, 1998) que tiene como base la monogamia, la fidelidad y la confianza en la pareja; desde ahí sostienen la creencia de que aunque sus parejas estén lejos —por su condición de migrantes - también son "fieles" o "se portan bien”. En los siguientes testimonios se evidencian estas concepciones:

ENTREVISTADORA: ¿Te gustaría hacerte una prueba de VIH/sida?

EnTREvistaDA: Sí, pues dicen que es mejor prevenir que lamentar, pero sé que eso [el VIH] no se da en personas así...

ENTREVISTADORA: ¿En qué personas?

EntrevistadA: Así, porque la verdad yo sólo he andado con mi esposo.

Entrevistadora: Pero ¿sabes con quién ha estado tu esposo? Me dijiste que estuvo viviendo en Estados Unidos.

EnTREvistadA: (Risas) eso sí, no sé. No sé con quién anduvo. Pero él fue el único hombre de mi vida, hasta hoy, nadie me ha tocado más que él, soy mujer de un solo hombre, le soy fiel; él lo sabe y por eso yo creo que él también lo es (Cinthia, 28 años).

ENTREVISTADORA: ¿te ha dado miedo alguna vez que te dé sida?

ENTREVISTADA: No me da miedo porque pienso en Dios, yo no estoy haciendo nada malo y estoy tranquila. No lo pienso (Helena, 39 años, traducido del maya).

Entrevistadora: Juana ¿tú crees que la gente que sale a trabajar fuera de Tahdziú pueden adquirir el $\mathrm{VIH} /$ sida?

ENTREVISTADA: pienso que sí, hay mucho riesgo.

Entrevistadora: ¿y tú platicas de eso con tu esposo que trabaja en Mérida?

ENTREVISTADA: No, pero él le tiene mucho miedo a esa enfermedad. Hay muchas mujeres que sólo así andan, además no son limpias porque una mujer de ésas anda con muchos hombres. Él así lo dice, por eso cuando se va a trabajar no tiene amigos y no sale, se porta bien (Juana, 29 años). 
Sólo cinco de las mujeres entrevistadas en ambas localidades declararon tener miedo de que su pareja le transmita el VIH/sida. Sin embargo, resulta interesante destacar que no hay correlación alguna entre las mujeres que expresaron este miedo o percepción subjetiva de estar en riesgo y las que supuestamente reciben más información sobre el tema por contar con las pláticas y talleres del Programa Oportunidades, lo que nuevamente invita a evaluar los componentes cualitativos de este tipo de programa y su impacto, en términos de prácticas de autocuidado en las mujeres. Esto sin dejar de reconocer que la vulnerabilidad de estas mujeres requiere mucho más que recibir información para modificar sus valores y prácticas; implica cambios de fondo en su contexto sociocultural y económico y transformaciones en la construcción de su identidad femenina.

Ninguna de las participantes sabe a ciencia cierta si su marido tiene VIH, pero tampoco toman medida alguna para prevenirse de su potencial adquisición. Muchas veces porque, aunque tienen miedo a la enfermedad, confían en su pareja y eso les hace creer que sólo tienen relaciones sexuales con ellas y que las cuidan. Otras veces hablan desde un lugar de impotencia, pues aunque no confían del todo en su pareja o ya saben que estuvieron con otras mujeres, sienten que no pueden hacer nada al respecto, debido a que en este contexto la exigencia del uso del condón es visto como una señal de desconfianza hacia la pareja, que bajo circunstancias como el alcohol puede llevar a ser objeto de violencia:

Sí me da miedo pensar que mi esposo cuando sale a trabajar esté con otra mujer, pero se lo he preguntado y me dice que no, que no lo hace porque él me va a cuidar, y la verdad no sé, un tiempo dudé así cuando escuché... o sea a una mujer le pasan cosas por su cabeza como pensar que ya se acostó con una vieja y luego se viene a acostar conmigo, que es un desgraciado, que no sé qué, que por allá... pero ¿pues qué más? Allá él si se mete con alguien y no se cuida, yo no puedo hacer nada, porque no veo lo que hace cuando sale de aquí y tampoco puedo exigirle que se ponga un condón porque no tengo pruebas de que se haya metido con otra mujer... Una vez cuando llegó yo sospechaba que había estado con otra y como ya estaba con tragos se enojó, me empezó a gritar y hasta intentó pegarme (Dalila, 21 años).

Casos como el de Dalila hablan de una situación de vulnerabilidad donde ella sospecha que su marido se ha acostado con otras mujeres y expresa miedos, dudas y una percepción de estar en riesgo, pero aun así no toma medidas para protegerse o dar un seguimiento objetivo a su estado de salud, mediante el uso del condón o la realización de la prueba del VIH, de manera precautoria, a fin de contar un diagnóstico oportuno y emprender acciones para proteger su salud, en caso de haber adquirido esta enfermedad. Dalila, como otras de las mujeres entrevistadas, muestra una sensación de indefensión aprendida, es decir la creencia, ya naturalizada, de que no puede hacer nada para cambiar su situación o destino. Dicha indefensión forma parte de su condición de vulnerabilidad, adquirida a través de la socialización de género a la que son expuestas las mujeres de estas comunidades. 
En lo que se refiere a los hábitos de autocuidado de las mujeres participantes, éstos son muy diversos y tienen poca consistencia o estructura. La mayoría de ellas, como ya apuntamos, no suele realizarse de forma voluntaria pruebas diagnósticas como parte de una rutina de autocuidado, sólo se las hacen cuando no les queda más remedio, bajo situaciones como la boda, el embarazo o el cumplimiento de un requisito para cobrar su beca del Programa Oportunidades. Ejemplo de ello es que sólo ocho de un total de 17 mujeres se habían realizado un examen como el Papanicolau, a pesar de que es una prueba que se ofrece a las usuarias de servicios de salud como parte de una política pública de detección y control temprano de Cáncer Cervicouterino (CACU), e incluso se condiciona su realización para recibir el apoyo económico del Programa Oportunidades.

En lo referente al tratamiento de molestias o infecciones "sencillas", las mujeres pueden acudir a consultar al centro de salud local, pero en muchos casos prefieren usar tratamientos que les recomienda una amiga, medicamentos que ven por la televisión o recetas de la medicina tradicional maya:

La enfermera me dijo: "Tenías muchas infecciones, por eso no baja tu menstruación”, porque cuando me metió esa cosa para revisarme, me raspaba y está saliendo sangre... No me dieron nada para curarme porque siempre que voy me ve otro ginecólogo diferente. Sólo me hicieron muchos exámenes... Cuando tengo relaciones sexuales con mi esposo y tengo un ardor, me lavo y tomo un poco de las hierbas que mi mamá empezó a traerme. Así me dejó de doler un poco (Norma, 20 años).

EnTREVISTADORA: ¿Alguna vez tuviste una infección vaginal?

EnTREvistadA: Sí, creo que dos veces. Tuve comezón, ardor vaginal y todas esas cosas, dos veces me ha pasado eso... pues como que veía los anuncios que pasaban en la tele, pues me parece que eran Canestén $V$; pues eso me compré. Se me quitó, y es muy así como dice, tres veces que tienes que usarlo (Cinthia, 28 años).

Hay muchos testimonios que expresan el temor, la desconfianza o la vergüienza que muchas mujeres tienen ante los médicos cuando el tema de la consulta se relaciona con problemas de su esfera sexual y reproductiva, aunque sólo se trate de estudios de rutina como el papanicolaou:

Apenas hace un año me hicieron el Papanicolaou aquí en el Centro de Salud... me dio miedo, lo pensé casi seis meses porque una señora que le hicieron su Papanicolaou le dio hemorragia. No sé qué es lo que le paso así; o tuvo miedo o la lastimaron o no sé. Porque yo también tuve miedo, digo "¿Qué tal si me lastiman? ¿Qué tal si me hacen así?" digo, y voy a abrir mis pies a la enfermera, el enfermero iAy no, no estoy loca! Digo. No, no fui (Dalila, 21 años).

También existen diversos mitos y miedos infundados relacionados con el tratamiento de las ITS:

Cuando tengas relación sexual te pasa y te contagia, me dijo el doctor: "Si tú ya te curaste y tu esposo viene y te haga relación, él también tiene infección y te lo pega 
otra vez —me dice-, por eso debe[n] de tomar medicina tu esposo y tú" [...]. Pero no las quiso tomar, como él trabaja y toma cosas de latería y come cosas de latería, si las toma se intoxica... Tenemos miedo porque un señor de aquí se queda blanco, blanco (Norma, 20 años).

En suma, se puede afirmar que las mujeres mayas parejas de hombres migrantes que fueron entrevistadas para este estudio no han adoptado de forma consistente y sistemática medidas para el autocuidado de su salud sexual y reproductiva y tampoco se perciben en una situación de riesgo de adquisición del $\mathrm{VIH}$, a pesar de encontrarse en un contexto de vulnerabilidad marcado por la condición de ser parejas de hombres migrantes. No obstante, esta falta de autocuidado y medidas de prevención entre este grupo de mujeres no debe juzgarse o entenderse como conductas individuales, aisladas, sino que han de comprenderse como resultado de un escenario en el que dominan diversas circunstancias como la baja escolaridad, la etnicidad, la pobreza y las construcciones sociales de género que terminan configurando condiciones de vulnerabilidad que sólo se remueven con políticas públicas y programas de acción que transformen las estructuras vigentes.

Sin embargo, detectamos que cuando las mujeres tienen acceso a información completa y precisa, de forma didáctica y en su lengua, sobre el VIH/sida y las ITS, así como cuando adquieren conciencia de la importancia de realizarse pruebas diagnósticas como parte de su rutina de autocuidado, esto en su conjunto funciona como una estrategia para tener mayor control de sus cuerpos, su vida sexual y la de sus parejas:

Le dije a mi marido, yo ya le pedí a la doctora que me haga mi prueba del VIH, porque yo sé que no me meto con otras personas. Ahora, si tengo algún problema, seguro que tú me lo trajiste —le dije-. Se espantó, se espantó mucho. Le dije "Si estoy enferma, tú me infectaste". "¿Y cuándo te van a dar el resultado?”- - me dice-, "Pues no sé", le dije, pero eso de que le haya dado temor me hace pensar que como que sabe que se mete con otras, creo sabe que lo voy a descubrir (Carolina, 23 años).

Este tipo de estrategia demuestra que la misma desigualdad de género es a veces utilizada como una herramienta de subversión. Sobre todo frente a temáticas tabú, las mujeres optan por estrategias veladas, casi subterráneas, más que por el enfrentamiento directo con la pareja. En estos casos podemos observar lo que Foucault (1977) describe como micro-mecanismos de poder usados por los subordinados de una relación, como formas de resistencia a las estructuras de poder hegemónicas o dominantes.

Otra estrategia orientada al autocuidado entre las mujeres es compartir la información aprendida con sus parejas, su familia y otras mujeres de la comunidad, para ir creando una red de conocimientos y valores compartidos que se traduzca gradualmente en prácticas de atención y cuidado de la salud: 
ENTREVISTADA: Ahora tenemos información, pero es necesario que hablemos de esto que escuchamos y aprendemos con nuestras familias para que no sucedan más esas enfermedades. Yo se lo tengo que explicar a mi esposo, a mi familia y a otras mujeres. Quienes lo escuchen también tienen que hablarlo con otras mujeres, platicarlo entre ellas, en su familia y en sus compañeras. Sólo así todos aprenderemos y podemos aprender a cuidarnos; sólo así podemos evitar enfermarnos (Helena, 39 años, traducido del maya).

En suma, las mujeres mayas han puesto en práctica algunas estrategias, abiertas o encubiertas, para aminorar las posibilidades de adquisición del VIH/sida. Por ejemplo, detectamos que las bien informadas trasmiten esos conocimientos a su familia y a sus maridos e incluso la usan para amenazar o chantajear a sus parejas, con el fin de tener más control sobre la sexualidad de éstas. La prueba diagnóstica tiene esta doble función para ellas: conocer su estado de salud y controlar el de sus maridos, haciéndolos responsables de sus actos ante ellas. Sin embargo, estas estrategias articuladas desde lo individual resultan insuficientes para contrarrestar la vulnerabilidad social y de género en la que se encuentran inmersas estas mujeres, misma que aumenta significativamente sus posibilidades de adquisición de alguna ITS o el VIH/sida a través del contacto sexual con sus parejas migrantes.

\section{Reflexiones finales}

Como se ha podido entrever a través de los testimonios presentados, las mujeres entrevistadas se encuentran en un contexto marcado por la vulnerabilidad social y de género que incrementa sus posibilidades de adquisición del $\mathrm{VIH} / \mathrm{sida}$. En realidad, se trata de muchos escenarios de vulnerabilidades sobrepuestas. En la dimensión de las condiciones materiales ubicamos factores como las desigualdades de acceso a la educación, la salud y el trabajo remunerado, el monolingüismo mayahablante y la carencia de infraestructura y servicios públicos en los que vive la población maya del sur del estado. Todo ello, ligado a su vez a la emergencia del fenómeno migratorio de sus parejas como una estrategia de sobrevivencia para hacer frente a la economía familiar. Por otro lado, en la dimensión de las condiciones simbólicas vinculadas a la vulnerabilidad que marca la vida de estas mujeres se puede distinguir su posición desigual en las relaciones de género que desde pequeñas las excluye del acceso a conocimientos claros y científicos sobre sexualidad, pero también limita el poder y control que pueden ejercer sobre sus cuerpos y personas.

La desigualdad de género también se expresa en la manera como construyen su sistema de significados en torno al ser mujer, el amor y la pareja, que las vincula a relaciones de sumisión y dependencia de sus parejas en lo económico, pero también en todo lo referente al cuidado del cuerpo, la reproducción y la vivencia de su sexualidad. Entre los diversos mandatos de género que han internalizado, 
el amor romántico (Giddens, 1998) se vuelve una limitante para el cuidado de su persona, en la medida que la desconfianza, tomar medidas precautorias y marcarle límites a la pareja se traducen como actos de desamor, que, cuando son expresados, en este contexto pueden dar paso a la violencia. En definitiva, la vulnerabilidad de género en las mujeres cruza todos los otros factores a los que están expuestas, potenciándolos y aumentando su desprotección.

Sin duda el análisis de la información vertida en las entrevistas por las mujeres mayas parejas de migrantes aporta suficientes elementos para identificar los factores que están presentes en este contexto, y que configuran un escenario de vulnerabilidad social y de género asociado a la potencial adquisición del $\mathrm{VIH} / \mathrm{sida}$ entre estas mujeres. En este sentido, las políticas públicas que se articulen para dar respuesta a este problema deberán apuntar en todo momento a transformar la raíz (brindar alternativas de empleo en la localidad, medidas para combatir la deserción escolar y el analfabetismo, generación de opciones productivas, transformación de premisas de género), pero no hay que perder de vista que este tipo de políticas sólo tendrá efecto a largo plazo. Por ello, consideramos que sin perder de vista las políticas y acciones de largo alcance, paralelamente se deben proponer medidas o estrategias de prevención primaria y secundaria que tengan impacto a mediano o corto plazo. Este tipo de acciones, si bien no resolverán el problema de raíz, si aminorarán o paliarán los impactos negativos que las actuales condiciones de vulnerabilidad están teniendo en la salud de las mujeres del contexto investigado.

En este sentido, vislumbramos que fomentar la detección temprana del VIH/ sida entre las mujeres mayas parejas de migrantes es una estrategia de prevención secundaria que de forma realista, aunque no evita, sí disminuye el impacto que la adquisición del VIH tendría en la esperanza y calidad de vida de estas mujeres. La implementación de esta estrategia implicaría crear materiales didácticos y espacios de información y reflexión a través de los cuales las mujeres aumenten su percepción de que se encuentran en una situación de riesgo respecto a adquisición del VIH. A la vez que identifiquen la realización de la prueba de VIH al menos una vez al año, como una medida de autocuidado de su salud. Consideramos que esta acción influirá indirectamente en el comportamiento sexual de sus parejas, incitándolos a tomar más precauciones y hacerse responsables por la salud sexual de ambos.

La estrategia de detección temprana propuesta conlleva necesariamente mejorar el trabajo con el sector salud a nivel regional para sensibilizar al personal sobre las situaciones de vulnerabilidad a las que se enfrentan los migrantes y sus parejas en las comunidades, a fin de que desarrollen protocolos estrictos que ofrezcan la prueba a esta franja de la población, a la par que intensifiquen las campañas de prevención tradicionales.

Otros factores que facilitarían el acercamiento de la población para realizarse la prueba son la cercanía y confianza con el personal de salud, la confidencialidad del examen y una atención rápida y oportuna (Araya et al., 2013). En el contexto 
investigado resulta de especial relevancia, que los prestadores de servicios de salud conozcan y hablan la lengua materna de los usuarios - en este caso el idioma maya-, y que adapten sus servicios a un esquema intercultural de atención en salud.

A propósito de la estrategia de promover la detección temprana u oportuna del VIH como una medida de prevención secundaria entre las mujeres mayas parejas de migrantes se debe señalar que en la actualidad esta medida constituye una forma de prevención que va cobrando fuerza en contextos de vulnerabilidad, pero que todavía plantea muchos desafíos y retos. Al respecto se sabe que el diagnóstico tardío del $\mathrm{VIH}$ ha representado un problema constante a nivel mundial. En Europa y Estados Unidos, las estadísticas muestran que entre el 22 y 83\% de las personas infectadas fueron diagnosticadas en la etapa de sida, evitando la posibilidad de actuar oportunamente para mejorar la calidad de vida del paciente y evitar futuras infecciones (Araya et al., 2013).

Por último, resulta importante enfatizar que si bien, como se argumentó antes, no es posible dejar de lado las estrategias o acciones de prevención de $\mathrm{VIH} / \mathrm{sida}$ con impacto a corto o mediano plazo, por ningún motivo éstas deben de substituir o hacer que se pierdan de vista las políticas públicas y programas de acción orientados a transformar desde las entrañas los factores estructurales que están en la base de la vulnerabilidad con la que viven y enfrentan hoy los procesos de salud-atención-enfermedad determinados grupos sociales, en el presente caso las mujeres mayas que son parejas de hombres migrantes en el estado de Yucatán. 


\section{BIBLIOGRAFÍA}

Araya, Alejandra et al.

2013 "Facilitadores y barreras que enfrentan las personas al tomarse el test de ELISA para el diagnóstico del VIH: revisión de la literatura”, Revista Chilena de Infectología, 30 (3): 638-643.

Breilh, Jaime

2003 Epidemiología crítica. Ciencia emancipadora e interculturalidad. Buenos Aires: Lugar editorial.

Bronfman, Mario y René Leyva

2008 "Migración y Sida en México", 25 años de SIDA en México: Logros, desaciertos y retos, pp. 241-258, José Córdova et al. (eds.). México: Secretaría de Salubridad y Asistencia, Instituto Nacional de Salud Pública, Centro Nacional para la Prevención y Control del VIH/sida.

Bronfman, Mario, Patricia Uribe, David Halperin y Cristina Herrera

2001 "Mujeres al borde... vulnerabilidad a la infección por VIH en la frontera sur de México", Mujeres en las fronteras: trabajo, salud y migración (Belice, Guatemala, Estados Unidos y México), pp. 15-31, Esperanza Tuñón Pablos (coord.). México: El Colegio de la Frontera Sur, El Colegio de Sonora, El Colegio de la Frontera Norte y Plaza y Valdés.

Centro Nacional para la Prevención y el Control del VIH/SIDA

2013 Vigilancia Epidemiológica de casos de VIH/SIDA en México. Registro Nacional de Casos de SIDA. Actualización al cierre de 2013. México: Secretaría de Salud, Dirección General de Epidemiología, Centro Nacional para la Prevención y el Control del VIH/SIDA, <http://www.censida.salud.gob.mx/descargas/epidemiologia/RN_CIERRE_2013.pdf $>$.

Consejo Nacional de Evaluación de la Política de Desarrollo Social

2012 Informe de pobreza y evaluación en el Estado de Yucatán. México: Consejo Nacional de Evaluación de la Política de Desarrollo Social, Comisión Nacional de Protección Social en Salud.

2008 Lineamientos para la capacitación del personal en salud en la Estrategia de Fortalecimiento de los Talleres Comunitarios (EFTC). Dirección General del Programa Oportunidades, <http://www.seguropopular.salud.gob.mx/imagenes/contenidos/Oportunidades/lineamientos2012.pdf $>$.

D’Aubeterre-Buznego, María Eugenia

2000 "Mujeres y espacio social transnacional: Maniobras para renegociar el vínculo conyugal", Migración y relaciones de género en México, pp. 65-85, Dalia Barrera y Cristina Oehmichen C. (eds.). México: Gimtrap y Universidad Nacional Autónoma de México.

Fernández, Ana María

1993 La mujer de la ilusión. Pactos y contratos entre hombres y mujeres. Buenos Aires: Paidós. 
Flores Palacios, Fátima

2013 "El VIH Sida, síntoma de vulnerabilidad", Representaciones Sociales y Contextos de Investigación con Perspectiva de Género, pp. 81-100, Fátima Flores Palacios (coord.). México: Universidad Nacional Autónoma de México, Centro Regional de Investigaciones Multidisciplinarias.

Foucault, Michel

1977 Historia de la sexualidad, vol. 1, La voluntad de saber. México: Siglo XXI.

Giddens, Anthony

1998 La trasformación de la intimidad. Sexualidad, amor y erotismo en las sociedades modernas. Madrid: Ediciones Cátedra.

Herrera, Cristina y Lourdes Campero

2002 "La vulnerabilidad e invisibilidad de las mujeres ante el VIH/SIDA: constantes y cambios en el tema”, Salud Pública de México, 44 (6): 554-564.

Instituto Nacional de Estadística y Geografía

2010 Principales resultados del Censo de Población y Vivienda 2010. México: Instituto Nacional de Estadística y Geografía.

Instituto para el Desarrollo de la Cultura Maya del Estado de Yucatán, Universidad Tecnológica Metropolitana y Colegio de Bachilleres del Estado de Yucatán

2008 Diagnóstico regional sobre migración en Yucatán. Mérida, México: Universidad Tecnológica Metropolitana.

Keijzer, Benno de

1997 "El varón como factor de riesgo: masculinidad, salud mental y salud reproductiva", Género y salud en el sureste de México, pp. 123-145, Esperanza Tuñón (coord.). México: El Colegio de la Frontera Sur y Universidad Juárez Autónoma de Tabasco.

2006 "Hasta que el cuerpo aguante: género, cuerpo y salud masculina”, La Manzana, 1 (1): 23-56.

Leyva, René y Marta Caballero

2009 Las que se quedan: Contextos de vulnerabilidad a ITS y VIH/SIDA en mujeres compañeras de migrantes. México: Instituto Nacional de Salud Pública.

Magis, Carlos, Enrique Bravo, Cecilia Gayet, Pilar Rivera y Marcelo de Luca

2008 El VIH y el Sida en México al 2008: hallazgos, tendencias y reflexiones. México: Centro Nacional para la Prevención y el Control del VIH/SIDA.

Mann, Jonathan

1996 "Human Rights and AIDS: the Future of the Pandemic", Gaceta Médica de México, 132 (1): 113-121.

Mora, Luis

2002 Las fronteras de la vulnerabilidad: Género, migración y derechos sexuales y reproductivos. Santiago: Fondo de Población de Naciones Unidas. 
ONUSIDA

2008 Informe sobre la epidemia mundial de Sida. Ginebra: Organización de las Naciones Unidas.

Pedrosa, Laura

2004 "Saberse infectadas. Repercusiones de la detección de VIH en mujeres diagnosticadas durante el embarazo", Desacatos, 16: 148-170.

Pizarro, Roberto

2001 La vulnerabilidad social y sus desafíos: Una mirada desde América Latina. Serie de estudios estadísticos y prospectivos. Santiago de Chile: Naciones Unidas y Comisión Económica para América Latina y el Caribe.

Quintal, Rocío

2007 "Condiciones de posibilidad en la familia para la construcción de sujetos de derechos sexuales: El caso de las jóvenes yucatecas", tesis de Doctorado en Ciencias Sociales. México: Universidad Autónoma Metropolitana-Xochimilco.

2011 "Impacto de la migración en las relaciones de género dentro de las familias ‘que se quedan' del municipio de Tunkás, Yucatán”, Migración internacional en Yucatán. Transformaciones económicas, sociales y culturales en una comunidad migrante, pp. 113-143, Martín Echevarría, Marisol Cen, Gretty Escalante y Rocío Quintal (coords.). México: Consejo Nacional de Ciencia y Tecnología, Universidad Anáhuac y Universidad del Mayab.

Quintal, Rocío y Ligia Vera

2014 "Migración, etnia y género: tres elementos claves en la comprensión de la vulnerabilidad social ante el VIH/SIDA en población maya de Yucatán", Península, IX (2): 99-130.

Quintal, Rocío, Ligia Vera, Leticia Paredes y Alina Marín

2012 "Prevalencia del VIH/sida y factores socioculturales asociados, para el desarrollo de estrategias de prevención entre migrantes mayas yucatecos", Proyecto de Investigación Fondo Mixto y Consejo Nacional de Ciencia y Tecnología 169279. México: Centro de Investigaciones Regionales "Dr. Hideyo Noguchi” de la Universidad Autónoma de Yucatán. Inédito.

Rubio, Eusebio

1994 "Introducción al estudio de la sexualidad humana: conceptos básicos en sexualidad humana”, Antología de la Sexualidad Humana, tomo I, pp. 114-135. México: Consejo Nacional de Población y Miguel Ángel Porrúa.

Ruz, Mario Humberto

2006 Mayas. Primera parte. México: Comisión Nacional para el Desarrollo de los Pueblos Indígenas y Programa de las Naciones Unidas para el Desarrollo (Colección Pueblos indígenas del México Contemporáneo). 